\title{
Expression of a Bifunctional Chimeric Protein A-Vargula hilgendorfii Luciferase in Mammalian Cells
}

BioTechniques 20:116-121 (January 1996)

\author{
Y. Maeda, H. Ueda, T. Hara, J. \\ Kazami $^{1}$, G. Kawano ${ }^{1}$, E. \\ Suzuki and T. Nagamune \\ The University of Tokyo, Tokyo, \\ ${ }^{1}$ Toray Medical Devices \& Diag- \\ nostics Research Laboratory, \\ Shiga, Japan
}

\section{INTRODUCTION}

Bioluminescent proteins are gaining increased importance in detection and quantitation of biological substances, due to their high sensitivity and the high rate at which assays can be performed. However, the wild-type Photinus pyralis luciferase is unstable, which has hindered its use in immunoassays. Recently, the complete nucleotide sequence of the structural gene for stable luciferase of the marine ostracod crustacean Vargula hilgendorfii $(4,8)$ (formerly known as Cypridina hilgendorfii) has been determined (16). This has enabled us to consider this gene as a candidate for obtaining a bifunctional immunoreagent. The primary structure consists of a single polypeptide chain of 555 amino acids with two potential glycosylation sites. We have employed this enzyme for the following reasons: (i) The enzyme is infinitely stable at room temperature in a dried state. (ii) The light-emitting reaction is very simple, consisting of the oxidation of luciferin by molecular oxygen in the presence of Vargula luciferase; the reaction also does not involve energy-rich compounds like ATP $(15,20)$. (iii) Product inhibition is not observed.

As the second moiety for conjugation, we have used the well-documented protein A of Staphylococcus aureus (22), which binds to the Fc region of various mammalian IgGs. Protein A has five homologous domains $(\mathrm{E}, \mathrm{D}, \mathrm{A}$, $\mathrm{B}$ and $\mathrm{C}$ ), and we have utilized the $\mathrm{D}$ domain (SpA-D) for our construction of the chimeric protein. Since chemical conjugation often results in loss of en- zyme activity and a decrease in yield due to the formation of unexpected homodimers, we have conjugated the two moieties at the gene level, thus obtaining a stoichiometrically controlled product. Such chimeric proteins should retain their bifunctional properties and hence be useful for immunoassays that rely on both binding properties and enzymatic activity for the sensitive detection of antigen or antibody. In this paper we demonstrate how we successfully obtained a chimeric protein having both antibody binding and luminescent properties, by the introduction of a peptide link between the two moieties. The bipartite protein seems promising for use in sensitive immunoassays.

\section{MATERIALS AND METHODS}

Oligonucleotides were synthesized using an Applied Biosystems automated DNA synthesizer (Tokyo, Japan). All amplifications of DNA were done using Pyrococcus furiosus (pfu) DNA polymerase obtained from Stratagene (La Jolla, CA, USA). Polymerase chain reaction (PCR) was performed in a DNA Thermal Cycler from PerkinElmer (Takara, Tokyo, Japan). The strain of Escherichia coli used for propagation of DNA was XL1-Blue (Stratagene). Luciferin was chemically synthesized in accordance with the method of Inoue et al. (7). All other enzymes were from Takara (Tokyo, Japan) and New England Biolabs (Beverly, MA, USA). The chemicals and other reagents were obtained from Sigma Chemical (St. Louis, MO, USA) and Kanto Chemicals (Tokyo, Japan). 


\section{Gene Construction}

Expression plasmids were constructed by standard techniques (14). The protein A-Vargula luciferase fusion vector (pRSVPAcluc) encoding a mouse $\mathrm{V}_{\mathrm{NP}}$ signal sequence (12) and single $\mathrm{Fc}$ binding domain (SpA-D) from $S$. aureus fused upstream of the mature form of Vargula luciferase (Pro29-Gly555) for expression in mammalian cells was constructed as follows: To construct DNA encoding SpA-D, protein A fusion vector pRIT2T (Pharmacia Biotech, Uppsala, Sweden) was used as a template for PCR. Fifty picomoles each of primers 5'-GTCTGCAGGCGCAACAAAATAACTT-3' and 5'-GGCTGCAGCTTAAGACTTACCTGCTTGAGATTGCTTTAAT-3', 1 ng of pRIT2T plasmid, 200 $\mu \mathrm{M}$ dNTP, $20 \mathrm{mM}$ Tris-HCl pH 8.2, 10 $\mathrm{mM} \mathrm{KCl}, 2 \mathrm{mM} \mathrm{MgCl}_{2}, 6 \mathrm{mM}$ $\left(\mathrm{NH}_{4}\right)_{2} \mathrm{SO}_{4}, 0.1 \%$ Triton ${ }^{\circledR} \mathrm{X}-100,10$ $\mathrm{ng} / \mu \mathrm{L}$ nuclease-free bovine serum albumin (BSA) and 2.5 units $p f u$ DNA polymerase in $100 \mu \mathrm{L}$ reaction mixture were used for PCR performed in a DNA Thermal Cycler. All PCR were carried out for 30 cycles of denaturation $\left(1 \mathrm{~min}\right.$ at $\left.94^{\circ} \mathrm{C}\right)$, annealing $(1 \mathrm{~min}$ at $\left.55^{\circ} \mathrm{C}\right)$ and extension $\left(2 \mathrm{~min}\right.$ at $\left.72^{\circ} \mathrm{C}\right)$. The amplified fragment digested with Pst I was inserted into PstI-digested pUC-type vector pTV118N (Takara) into which had been inserted a 574-bp $N c o$ I fragment of pRSVV $\mu$ ERCA (21) containing mouse $\mathrm{V}_{\mathrm{NP}}$ signal sequence at its $\mathrm{NcoI}$ site. The recombinant with the correct orientation was selected by restriction analysis and nucleotide sequencing using Sequenase ${ }^{\circledR}$ (United States Biochemical, Cleveland, $\mathrm{OH}$, USA) and was confirmed as the D domain of protein A. This plasmid was digested with $N c o$ I and $A f l I I$ to get a fragment of SpA-D that has $\mathrm{V}_{\mathrm{NP}}$ Ig signal sequence at its $5^{\prime}$ end and a splice donor sequence at its $3^{\prime}$ end. The purified fragment was ligated with $\mathrm{NcoI}-$ AflII-digested pRSVV $\mu$ ERCA of which the $N c o$ I site in the simian virus 40 (SV40) early promoter region had been removed with T4 DNA polymerase and denoted pRSVPAER. To insert luciferase into this, the intron between mouse $\mathrm{IgM} \mathrm{CH} 2$ and $\mathrm{CH} 3$ with splicing consensus sequence was amplified by PCR using primers 5'-
GTCTTAAGTAGGTTTGGGGG-3' and 5'-GACCTGCAGGCAAGAGAACACTGTG-3' that contained the AflII and Sse 8387I restriction sites, respectively, and plasmid pRSVV $\mu$ ERCA as template. The $1.58 \mathrm{-kbp}$ Vargula luciferase fragment was obtained by PCR using 5'-TGCCTGCAGGTCCGTCAAGTACACCAACAG-3' (otherwise called cluc back) and 5'-ACGCGGCCGCTTATTGGCATTCAGGTGGTA$3^{\prime}$ having Sse8387I and NotI sites, respectively, as primers, and pSTCL81 plasmid (Kazami et al., unpublished) having the entire cDNA as the template DNA. The PCR conditions and the buffer constituents were the same as for the amplification of the SpA-D-encoding fragment. Restriction endonuclease-digested PCR fragments were ligated subsequently to pRSVPAER at sites $A f l \mathrm{II}$ and NotI (modified the unique $\mathrm{XbaI}$ site with NotI linker), excising the EGFR fragment to yield the final construct-pRSVPAcluc having both SpA-D and luciferase coding regions, via intron, which would enable rapid exchange of exons. The expression plasmid pRSVPALcluc with linker (Gly) ${ }_{4}$ Ser between SpA-D and luciferase was constructed as above, but using primer 5 '-CCTGCAGGCGGTGGCGGATCGCCGTCAAGTACACCA-3' instead of cluc back. For the expression of wild-type luciferase in mammalian cells, a 1.6-kbp Asp718 fragment of the entire luciferase cDNA in pSTCL81 with its own secretion signal was introduced into expression plasmid pcDNA III (Invitrogen, San Diego, CA, USA) at the Asp 718 site in the desired orientation, resulting in plasmid pccluc.

\section{Expression in Mammalian Cells}

The simian COS-1 cell (Riken Cell Bank, Tokyo, Japan) was transfected with gel-filtrated plasmids by the DEAE-dextran method. The cells were cultured using Dulbecco's minimum essential medium (Nissui Pharmaceutical, Tokyo, Japan) containing $10 \%$ calf serum (Life Technologies, Gaithersburg, MD, USA) in a humidified $5 \%$ $\mathrm{CO}_{2}$ incubator at $37^{\circ} \mathrm{C}$. After 4 to 5 days of incubation, the culture supernatant and the adherent cells were collected for luciferase activity measure- ment. Stable transfectants of Vargula luciferase were obtained from dihydrofolate reductase-deficient $\mathrm{CHO}$ cells (CRL-9096; ATCC, Rockville, MD, USA) by cotransfection with 20 and 2 $\mu \mathrm{g}$ of pRSVPALcluc and pSV2dhfr (23), respectively, by the method of Chen and Okayama (3). The transfectants that had survived the nucleotidefree $\alpha$-MEM (Life Technologies) were amplified with increasing concentration of methotrexate from 0.020 to 1 $\mu \mathrm{M}$.

\section{Assay for Luciferase Activity}

The luciferase activity of the chimeric protein secreted in the culture medium as well as that of cytosolic extract was measured with an ATP photometer (Sai Technology, CA, USA) standardized with a $\left[{ }^{14} \mathrm{C}\right] 1$-hexadecane light source (5). The cytosolic extract was prepared in $1 \mathrm{~mL}$ of phosphatebuffered saline (PBS, pH 7.2), after sonicating cells with sonifier [Branson, Danbury, CT, USA] in the presence of protease inhibitors, leupeptin and aprotinin $(5 \mu \mathrm{g} / \mathrm{mL}$ each). Two microliters of $0.1 \mu \mathrm{g} / \mathrm{mL}$ luciferin were added per reaction volume, immediately before bioluminescent activity measurement.

\section{Protein Characterization and Western Blot Analysis}

The chimeric proteins obtained after transfection of COS-1 cells with plasmids pRSVPAcluc and pRSVPALcluc were each analyzed for luciferase activity. The IgG binding ability of the chimeric protein was primarily examined by measuring the luminescent activity of the Sepharose-bound luciferase after incubation of $300 \mu \mathrm{L}$ of culture supernatant containing the chimeric protein with $20 \mu \mathrm{L}$ of human IgG-Sepharose 6FF (Pharmacia Biotech, Uppsala, Sweden) for $1 \mathrm{~h}$ at $4^{\circ} \mathrm{C}$ on a rotating wheel after removal of the unbound chimeric protein with PBS.

For confirmation of the expression of the chimeric SpA-D-luciferase, Western blotting was performed as follows: The cytosolic extract was prepared by lysing about $8 \times 10^{5}$ cells with $100 \mu \mathrm{L}$ of PBS containing 1\% Triton $\mathrm{X}-100$, and $10 \mu \mathrm{L}$ of the above extract were taken. The proteins were resolved 
by $7.5 \%$ sodium dodecyl sulfate (SDS)polyacrylamide gel electophoresis [as described by Laemmli (9)] and transferred overnight to nitrocellulose (18), blocked with 3\% locally available skimmed milk in TBST $(50 \mathrm{mM}$ Tris$\mathrm{HCl}, 150 \mathrm{mM} \mathrm{NaCl}, \mathrm{pH} 7.2$, containing $0.1 \%$ Tween 20). The filter was incubated serially with rabbit anti-luciferase antiserum (raised against recombinant Vargula luciferase) and peroxidase-conjugated goat anti-rabbit antibody (Tago, Burlingame, CA, USA) in TBST.

The chimeric proteins secreted in the culture supernatant as well as those of cytosolic extract were further analyzed for its IgG binding ability as follows: The Sepharose-bound protein was eluted with $1 \mathrm{~mL}$ of $0.1 \mathrm{M}$ acetate buffer of $\mathrm{pH} 3.3$, precipitated by the addition of $150 \mu \mathrm{L}$ of $20 \%$ trichloroacetic acid, centrifuged and electrophoresed as above. The IgG binding ability was evaluated by incubating the filter with peroxidase-conjugated rabbit IgG (The Binding Site, Birmingham, UK) in TBST. All blots were visualized by enhanced chemiluminescent detection system (Amersham International, Little Chalfont, Bucks, UK) for peroxidaselabeled antibodies.

\section{Immuno-Luminometric Assay Using the Chimeric Protein}

Standard curve for human IgG was determined as follows: Various amounts of IgG-Sepharose 6FF were taken, and the volume of the dispersed beads were adjusted to $20 \mu \mathrm{L}$ with Sepharose 6B. These beads were incubated with $300 \mu \mathrm{L}$ of the culture supernatant containing chimeric protein at $4^{\circ} \mathrm{C}$ on a rotating wheel for $1 \mathrm{~h}$. The beads were washed 4 to 5 times with 1 $\mathrm{mL}$ PBS to wash out the unbound (SpA-D-luciferase) protein. The bioluminescent activity of luciferase bound to the beads was measured after dispersing the beads in $500 \mu \mathrm{L}$ of PBS and injecting luciferin just before measurement as described above.

For sandwich ELISA format, monoclonal anti-trinitrophenol (TNP) mouse antibody $2 \mathrm{E} 3\left(\mathrm{IgG}_{1}\right)$ was assayed (10). To obtain TNP-Sepharose, $1 \mathrm{mg} / \mathrm{mL}$ of sodium salts of trinitrobenzene sulfonate (Wako, Osaka, Japan) was con- jugated to EAH-Sepharose 4B (Pharmacia Biotech) in $2 \%$ sodium borate buffer for $1 \mathrm{~h}$ at $20^{\circ} \mathrm{C}$. Twenty microliters of TNP-Sepharose were taken, and 0 to $2 \mu \mathrm{L}$ of $1 \mu \mathrm{g} / \mu \mathrm{L} 2 \mathrm{E} 3$ antibody in $1 \mathrm{~mL}$ of PBS were incubated for $1 \mathrm{~h}$ at $4^{\circ} \mathrm{C}$ on a rotating wheel. Subsequently, $10 \mu \mathrm{g} / \mathrm{mL}$ rabbit anti-mouse IgG (Zymed, San Francisco, CA, USA) was similarly incubated in $1 \mathrm{~mL}$ PBS. The amount of rabbit IgG bound to Sepharose by 2 E3 antibody was assayed after incubating $300 \mu \mathrm{L}$ of the culture supernatant containing the chimeric protein for additional $1 \mathrm{~h}$.

\section{RESULTS}

\section{Plasmid Construction}

The expression vector, pRSVPAcluc consists of the gene coding for Vargula luciferase fused at the $3^{\prime}$-end of the D domain of protein A (SpA-D). Figure 1 shows a schematic structure of the vector pRSVPALcluc that has a linker of 5 amino acids inserted between SpA-D and luciferase.

\section{Protein Expression and Characterization}

When the COS-1 cell was transfected with plasmid pRSVPAcluc, bioluminescent analysis of the chimeric protein indicated that there was significant activity of luciferase both in the cell extract as well as in the culture supernatant when compared to that of mocktransfected cells. The results suggest that the expression of the chimeric protein in the COS-1 cell was successful and that the light-emitting property of luciferase was retained, even when conjugated with SpA-D. To confirm this, Western blot analysis of this chimeric protein using rabbit polyclonal antibody raised against $V$. hilgendorfii luciferase was performed. The main band was observed as shown in Figure 2 (lane 1) of about $76 \mathrm{kDa}$ as expected from comparison with that of luciferase alone (lane 4) (about $68 \mathrm{kDa}$ ), thus confirming that luciferase was fused to SpA-D. The variation in molecular weight of the chimeric protein from that of the calculated weight $(67.973$ $\mathrm{kDa})$ may be due to the posttranslation- al modifications. The IgG binding ability of the chimeric protein was then investigated. The culture supernatant of cells transfected with pRSVPAcluc was incubated with IgG-Sepharose 6FF for $1 \mathrm{~h}$. After repeated washings of the Sepharose beads to remove the unbound chimeric protein, the addition of luciferin showed no rise in photon counts and hence no luciferase activity could be observed. This indicated that the binding affinity of the chimeric protein to the Fc region of IgG is either lost or reduced considerably.

So that the properties of protein A could be restored, we introduced a linker between SpA-D and luciferase. We have chosen the amino acid sequence of the linker as GlyGlyGlyGlySer, derived from those used to connect heavy- and light-chain variable domain in single-chain antigen-binding proteins (6). We have selected this particular linker because it contains no basic residues that could be degraded by protease, and in addition, glycine residues have more conformational freedom than any other amino acid. The new protein was transiently expressed in the COS-1 cell. After observing that there was significant luciferase activity of the secreted chimeric protein as compared with mock-transfected culture medium, the IgG binding capability of the chimeric protein was examined. We found that the new chimeric protein bound to IgG-Sepharose, as evidenced from bioluminescent measurement of the Sepharose-bound chimeric protein. The

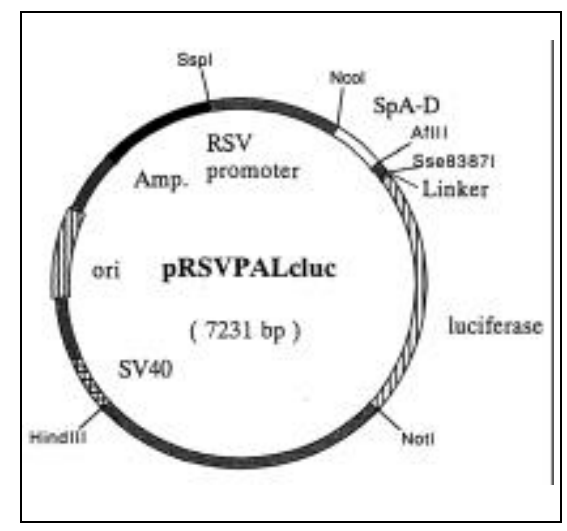

Figure 1. Schematic representation of the plasmid pRSVPALcluc. Gene encoding the entire cDNA of Vargula luciferase was fused at the C terminus of that encoding protein A ( SpA-D ). RSV: Rous sarcoma virus promoter, Amp:ampicillin resistance. 
cytosolic extract was electrophoresed on SDS polyacrylamide gel, blotted onto nitrocellulose paper and probed with anti-luciferase antibody, when a distinct band of molecular weight similar to that without linker was observed as seen in Figure 2 (lanes 1 and 2).

To further confirm the ability of SpA-D to bind to human and/or rabbit IgG, Western blot analysis with preimmune IgG was carried out. The cytosolic extract and the culture supernatants, purified with human IgG-Sepharose, were electrophoresed and transferred to nitrocellulose. Analysis of pRSVPAcluc-transfected cells using rabbit IgG peroxidase produced no desired band, confirming that the binding activity of SpA-D to human IgG had diminished although the luciferase activity could be retained. In contrast, cells transfected with pRSVPALcluc showed a distinct band in both the cytosolic extract and the culture supernatant (data not shown).

In order to obtain a stable transfectant, pRSVPALcluc plasmid was transfected into Chinese hamster ovary (CHO) cells. The cytosolic extract of

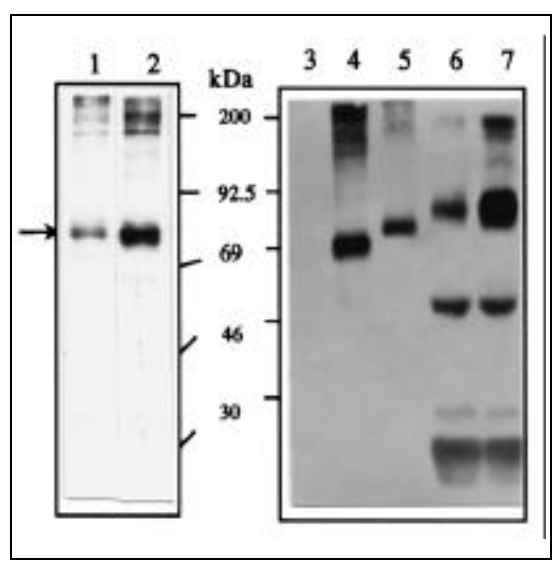

Figure 2. Western blot analysis of the chimeric proteins expressed in COS-1 and CHO cells. SDS-PAGE was performed and proteins were transferred to nitrocellulose. The blot was incubated with rabbit anti-luciferase and subsequently detected using anti-rabbit IgG peroxidase as detailed in Materials and Methods. Lanes 1 and 2, cell lysates of COS cells transfected with pRSVPAcluc and pRSVPALcluc, respectively; lane 3, mock transfection; lane 4, cell lysate of COS cells transfected with pccluc; lane 5, cell lysate of stably transfected $\mathrm{CHO}$ cells with plasmid pRSVPALcluc; lanes 6 and 7, culture supernatants of COS and CHO cells, respectively, transfected with pRSVPALcluc, after purification with IgG-Sepharose (bands of heavy and light chains of IgG detached from Sepharose are also seen). the transfectants exhibited a distinct band of about $76 \mathrm{kDa}$ (Figure 2, lane 5 ). The chimeric protein secreted in the culture medium was found to be of slightly higher molecular weight than those of cytosolic protein in both COS1 and CHO cells (lanes 6 and 7). There was no apparent proteolytic product, indicating that the chimeric protein was not susceptible to proteolytic degradation in culture supernatants nor under further treatments. Quantitation of the protein was performed by blot analysis, by comparison with that of known amounts of purified luciferase protein produced in yeast (13). The amount of the chimeric protein thus obtained in $\mathrm{CHO}$ cells after amplification with methotrexate, was estimated to be about $300 \mu \mathrm{g} / \mathrm{L}$ of culture supernatant.

To find out the specific activity of the chimeric protein, plasmid pccluc encoding the entire cDNA of Vargula luciferase with its own secretion signal in an expression vector pcDNA III having human cytomegalovirus promoter was constructed. The comparison of the bioluminescent activity of the chimeric luciferase with that of non-fused protein indicated that the specific activity of the chimeric luciferase was $50 \%$ (data not shown). This could be explained by a minor distortion in the native conformation of luciferase due to the fusion of protein A or some steric hinderance around the active site. However, the $\mathrm{pH}$ dependence and the thermal stability of the chimeric protein were almost the same as those of the native luciferase (data not shown), which indicates that the fusion to SpA-D did not significantly alter its characteristics.

To assess the bifunctionality and hence the applicability of the chimeric SpA-D-luciferase protein, we performed a number of immunoassays. Figure 3 illustrates the quantitative measurement of luciferase activity by incubating different amounts of human IgG-Sepharose with the chimeric protein. A linear relationship between the amount of human IgG covalently immobilized on Sepharose and the bioluminescent activity was observed. Using these beads, we could measure the bioluminescent activity up to the minimum concentration of $10^{-9} \mathrm{~g} / \mathrm{mL}$ of human immunoglobulin. 


\section{Research Reports}

An assay in the sandwich format is illustrated in Figure 4. TNP-Sepharose was used to capture anti-TNP antibody. A standard amount of mouse 2E3 antibody (IgG1) was incubated with TNPSepharose and subsequently with rabbit anti-mouse IgG for 1 hour. In the final step, the chimeric protein was incubated for an additional hour at $4^{\circ} \mathrm{C}$. The results indicate a proportional rise in the bioluminescent activity with increasing $2 \mathrm{E} 3$ antibody concentration.

\section{DISCUSSION}

Luminometric assays are known to be speedy and highly sensitive. In this paper, we have constructed a bifunctional chimeric protein by gene fusion using highly stable luciferase of $V$. hilgendorfii as one of the moieties. It is possible to semipermanently preserve the luminescent activity of Vargula luciferase protein in dehydrated condition (4). The enzyme has 34 cysteine residues that may contribute to the stability of the protein. Vargula luciferase catalyses the light-emitting reaction over a broad $\mathrm{pH}$ range with an optimum $\mathrm{pH}$ near 7.2 (2). Such unique properties of the luciferase have aroused our interest in designing a chimeric protein for diagnostic purposes. Mammalian cells, COS-1 and CHO cells are known to be functional hosts for luciferase production (17), but the expression of luciferase in $E$. coli using the pelB signal peptide-mediated secretion system (11) was not possible presumably due to the cysteine-rich characteristics of luciferase that might have impeded proper folding of luciferase.

We have chosen the monodomain of protein $\mathrm{A}$ as the other moiety of the chimeric protein. SpA-D having 61 amino acid residues is $78.9 \%$ homologous to the widely studied B domain. Incidently, SpA-D domain is $90.2 \%$ homologous to the recently reported synthetic composite immunoglobulin binder (SCIB) gene encoding a single IgG Fc binding domain (19). Significant luciferase activity was observed in the cytosolic extract and in the culture supernatant, when the chimeric protein was expressed using plasmid pRSVPAcluc in COS-1 cells. However, we found that this chimeric protein which

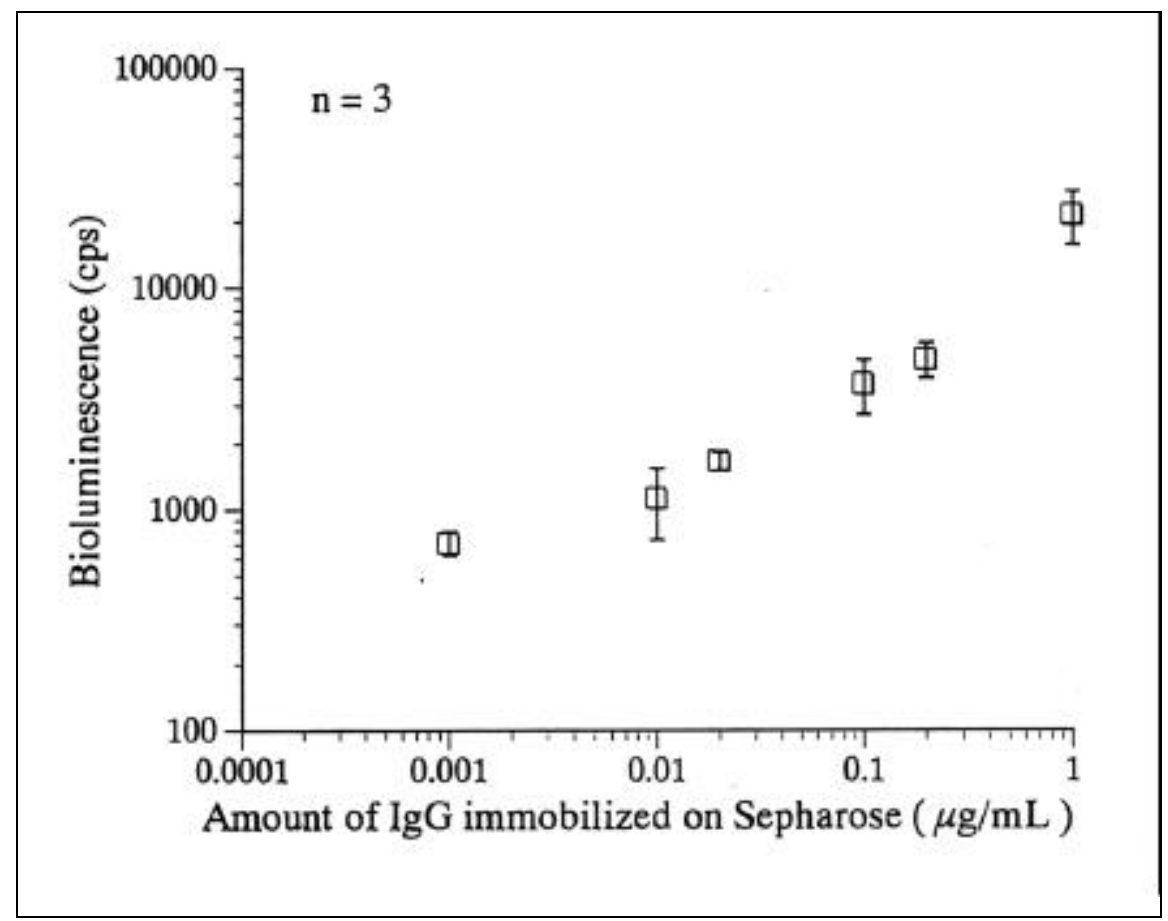

Figure 3. Dependence of the luminescent activity on human IgG concentration bound on Sepharose. Increasing concentration of human IgG-Sepharose was taken, and the luciferase activity of the IgG-bound chimeric protein was measured as described in Materials and Methods.

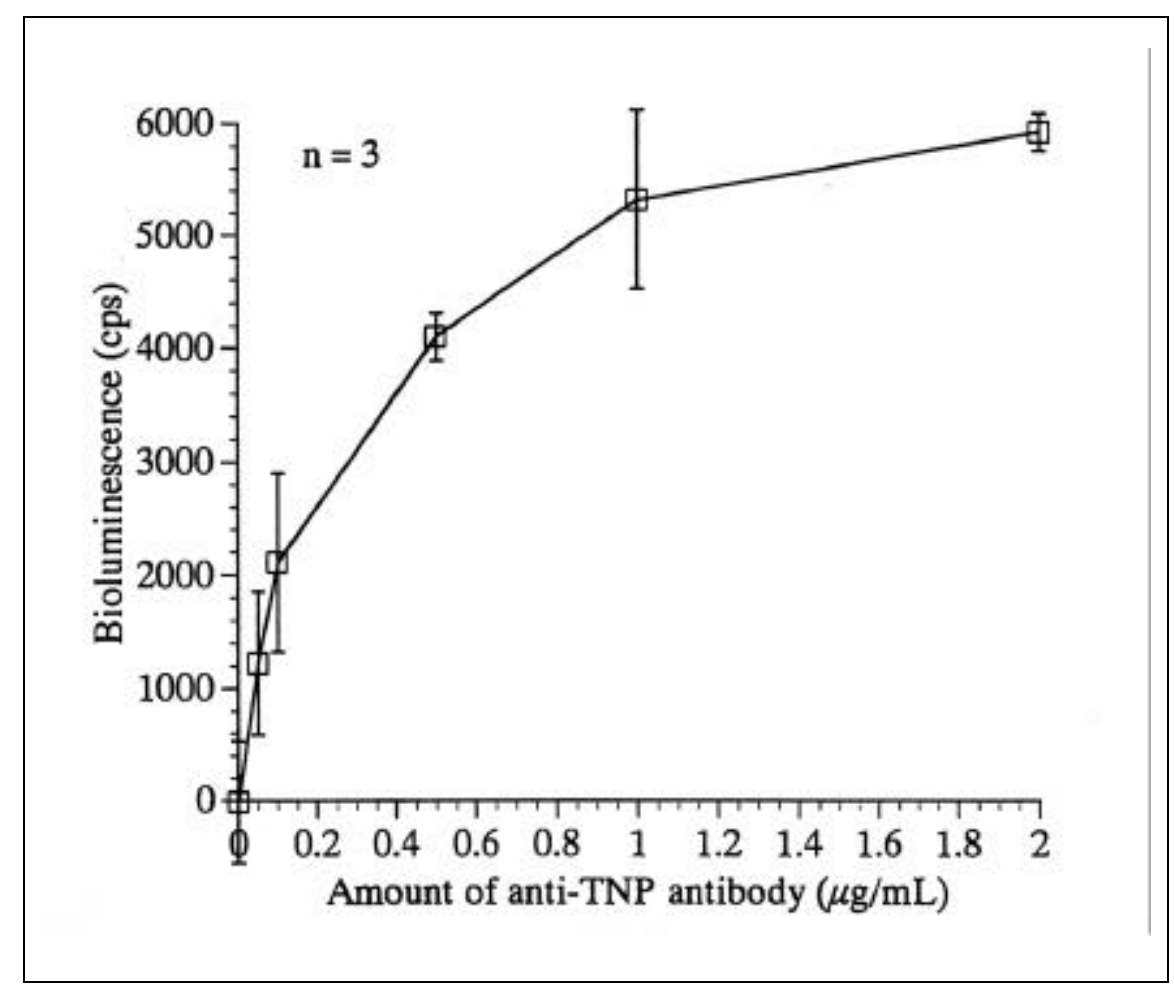

Figure 4. Sandwich immunoassay for anti-TNP antibodies. TNP was immobilized on Sepharose at a concentration of $1 \mu \mathrm{g} / \mathrm{mL} .20 \mu \mathrm{L}$ of TNP-Sepharose were taken and increasing amounts of mouse anti-TNP (IgG1) were added. Subsequently, $1 \mu \mathrm{g} / \mathrm{mL}$ of rabbit anti-mouse IgG was added, which was followed by the binding reaction between the chimeric protein and the Fc portion of rabbit IgG. The beads were washed thoroughly with phosphate-buffered saline (PBS) (pH 7.2) and readings taken immediately after the addition of luciferin. 
does not possess a linker between SpA$\mathrm{D}$ and luciferase had diminished IgG binding activity. The insertion of a linker of five amino acids could enable the Fc binding ability of protein A to be retained, and hence, SpA-D could be considered as a new functional domain of protein A, similar to SCIB (19). The retention of the $\mathrm{IgG}$ binding activity may be considered due to the restoration of the wild-type conformation of SpA-D required for efficient binding. It may be configured from the fact that the SpA-D domain loses its binding capability without the linker and that the conformation of the carboxy $(\mathrm{C})$-terminal region may be responsible for the overall stability of SpA-D, although not directly involved in the binding to the Fc region of IgG. During the preparation of this manuscript, Bottomley et al. (1) indicated that the third $\alpha$ helix, which is the $\mathrm{C}$-terminal region of the $\mathrm{B}$ domain of protein $\mathrm{A}$, contributes to the overall stability of the domain and to the formation of the IgG binding site in the first and second $\alpha$ helix. So we may conclude from our experiment that the linker between SpA-D and luciferase aids in proper conformation of the $\mathrm{C}$ terminal region of SpA-D, which in turn leads to higher affinity for the Fc region. Further lengthening of the linker motif to 15 amino acids (GlyGlyGlyGlySer $)_{3}$ did not alter the functional significance of both the moieties (data not shown).

Our purpose in constructing this chimeric protein was to evaluate its feasibility in immunoassays. Since the protein is efficiently secreted from the cells into the medium, we could directly use the culture medium containing the fusion protein for preliminary testing in immunoassays. A calibration curve was drawn for human IgG bound to Sepharose as shown in Figure 3 and an estimation of the detection limit for human IgG was approximately $10^{-10} \mathrm{M}$. The chimeric protein was further evaluated by performing a sandwich assay for the quantitation of antiTNP antibodies. It can be deduced from the activity of luciferase that the chimeric protein was specifically bound to antibody molecules and that no background signal was produced by nonspecific binding to other components.
In summary, we have successfully produced a chimeric protein possessing both the luminescent activity and antibody binding properties, which would be useful in detecting trace amounts of antibody or antigen in a simplified and rapid reaction.

\section{ACKNOWLEDGMENTS}

The authors are indebted to Dr. Y. Omiya for his constant encouragement and also for kindly providing us with the plasmid pSV2dhfr. We also appreciate Dr. H. Nishimura for his helpful discussions.

\section{REFERENCES}

1.Bottomley, S.P., A.G. Popplewell, M. Scawen, T. Wan, B.J. Sutton and M.R. Gore. 1994. The stability and unfolding of an IgG binding protein based on the $\mathrm{B}$ domain of protein A from Staphylococcus aureus probed by tryptophan substitution and fluorescence spectroscopy. Protein Eng. 7:1463-1470.

2.Chase, A.M. 1948. Effects of hydrogen ion concentration and of buffer systems on the luminescence of the Cypridina luciferin-luciferase reaction. J. Cell. Comp. Physiol. 31:175-192.

3.Chen, C. and H. Okayama. 1987. High efficiency transformation of mammalian cells by plasmid DNA. Mol. Cell. Biol. 7:8:27452752.

4.Harvey, E.N. 1952. Bioluminescence. Academic Press, New York. p.297-331.

5.Hastings, J.W. and G. Weber. 1963. Total quantum flux of isotropic sources. J. Opt. Soc. Am. 53:1410-1415.

6.Holliger, P., T. Prospero and G. Winter. 1993. "Diabodies": small bivalent and bispecific antibody fragments. Proc. Natl. Acad. Sci. USA 90:6444-6448.

7.Inoue, S., S. Sugiura, H. Kakoi and T. Goto. 1969. Cypridina bioluminescence: a new route for the synthesis of Cypridina luciferin and its analogs. Tetrahedron Lett. 20:16091610 .

8.Johnson, F.H. and O. Shimomura. 1978. Introduction to the Cypridina system. Methods in Enzymology, Vol. 57, Academic Press, New York. p.331-364.

9.Laemmli, U.K. 1970. Cleavage of structural proteins during assembly of the head of bacteriophage T4. Nature 227:680-685.

10.Makishima, F., S. Terada, T. Mikami and E. Suzuki. 1992. Interleukin-6 is anti-proliferative to a mouse hybridoma cell line and promotive for its antibody productivity. Cytotechnology 10:15-23.

11.Nasser, W., A. C. Awade, S. Reverchon and J. Robert-Baudouy. 1993. Pectate lyase from Bacillus subtilis: molecular characterization of the gene, and properties of the cloned enzyme. FEBS Lett. 335:319-326.
12.Neuberger, M.S. 1983. Expression and regulation of immunoglobulin heavy chain gene transfected into lymphoid cells. EMBO J. 2:1373-1378

13.Oshihara, W., J. Kazami, H. Nakamura, G. Kawano and T. Kunitomo. 1993. Luminescent analysis method using Vargula luciferase, p. 361-365. Bioluminescence and Chemiluminescence, John Wiley \& Sons, New York.

14.Sambrook, J., E.F. Fritsch and T. Maniatis. 1989. Molecular Cloning: A Laboratory Manual, 2nd ed. Cold Spring Harbor Laboratory Press, Cold Spring Harbor, NY.

15.Shimomura, O., F.H. Johnson and T. Masugi. 1969. Cypridina bioluminescence: light emitting oxyluciferin-luciferase complex. Science 164:1299-1300.

16.Thompson, E.M., E. Nagata and F.I. Tsuji. 1989. Cloning and expression of cDNA for the luciferase from the marine ostracod Vargula hilgendorfii. Proc. Natl. Acad. Sci. USA 86:6567-6571.

17.Thompson, E.M., E. Nagata and F.I. Tsuji. 1990. Vargula hilgendorfii luciferase: a secreted reporter enzyme for monitoring gene expression in mammalian cells. Gene 96:257262.

18.Towbin, H., T. Staehelin and J. Gordon. 1979. Electrophoretic transfer of proteins from polyacrylamide gels to nitrocellulose sheets: procedure and some applications. Proc. Natl. Acad. Sci. USA 76:4350-4354.

19.Trumble, W.R., M. Huang, J.W. West, J.L. Reasoner, J.L. Huang, C.L. Wang, J. Douthart and D.C.Birdsell. 1994. Gene synthesis and functional expression of a protein exhibiting monodomain IgG Fc binding. Protein Eng. 7:705-713.

20.Tsuji, F.I., R.V. Lynch, III and C.L. Stevens. 1974. Some properties of luciferase from the bioluminescent crustacean, Cypridina hilgendorfii. Biochemistry 13:5204-5209.

21.Ueda, H., M. Kikuchi, S. Yagi and H. Nishimura. 1992. Antigen responsive antibody-receptor kinase chimera. Bio/Technology 10:430-433.

22.Uhlen, M., B. Guss, B. Nilsson, S. Gatenbeck, L. Philipson and M. Linberg. 1984. Complete sequence of the Staphylococcal gene encoding protein A. J. Biol. Chem. 259:1695-1702.

23.Wernicke D. and H. Will. 1992. Generation of recombinant $\mathrm{CHO}(\mathrm{dhfr}-)$ cell lines by single selection for dhfr+ transformants. Analyt. Biochem. 203:146-150.

Received 30 March 1995; accepted 11 July 1995

Address correspondence to :

Hiroshi Ueda

Department of Chemistry and Biotechnology

Faculty of Engineering

The University of Tokyo

7-3-1, Hongo, Bunkyo-ku, Tokyo 113, Japan

Internet: hueda@bio.t.u-tokyo.ac.jp 